\title{
Etanercept in the treatment of plaque psoriasis
}

\author{
Thao U Nguyen \\ John Koo \\ Department of Dermatology, Psoriasis \\ and Skin Treatment Center, University \\ of California, San Francisco, San \\ Francisco, California, USA
}

\begin{abstract}
Etanercept is approved for the treatment of moderate to severe plaque psoriasis at a dose of $50 \mathrm{mg}$ twice weekly for 3 months followed by a maintenance dosage of $50 \mathrm{mg}$ weekly thereafter. Clinical studies have shown excellent efficacy, favorable benefit to side-effects ratio, and safe long-term usage. Extensive information on safety is available as etanercept has been used for many years for other indications such as rheumatoid arthritis and psoriatic arthritis and is the first of the tumor necrosis factor antagonists to gain approval in psoriasis.
\end{abstract}

Keywords: etanercept, plaque psoriasis, tumor necrosis factor antagonist

\section{Introduction}

Etanercept (Enbrel ${ }^{\circledR}$; Amgen-Wyeth) is a fully human tumor necrosis factor (TNF) receptor that reduces the inflammatory response by inhibiting interactions between TNF and cell-surface TNF receptors. Currently three TNF antagonists (adalimumab, infliximab and etanercept) are approved by the US Federal Drug and Administration (FDA) for the treatment of plaque psoriasis. Adalimumab and etanercept are indicated in the treatment of moderate to severe plaque psoriasis, whereas infliximab is indicated for severe plaque psoriasis. Adalimumab and infliximab are monoclonal antibodies, while etanercept is a soluble receptor fusion protein. Etanercept is also FDA approved for rheumatoid arthritis, psoriatic arthritis, juvenile idiopathic arthritis (JIA), and ankylosing spondylitis (AS).

Etanercept is an important therapeutic option in patients with moderate to severe plaque psoriasis. Studies have found it to have a high efficacy, favorable benefit to side-effects ratio, and safe long-term usage compared to other systemic treatments for psoriasis such as methotrexate, cycloporine, and PUVA. Effective treatment of psoriasis is needed because of the associated morbidity of psoriasis. Quality-of-life studies in patients with psoriasis attest to its significant impact on day to day activities and effect on personal relationships. ${ }^{1,2}$

Patients with psoriasis have increased disease-related inability to work, ${ }^{3}$ and face significant discrimination with resulting financial difficulties and depression. ${ }^{4}$ Psoriasis has also been associated with several comorbid conditions including obesity and cardiovascular disease. ${ }^{2,5,6}$ These data have prompted an awareness and interest in more aggressive management of psoriasis including biologic agents.

\section{Mechanism of action}

Etanercept is a fully soluble, human dimeric fusion protein with a molecular weight of $150 \mathrm{kDa}$. It consists of two extracellular ligand-binding domains of the human $75 \mathrm{kDa}$ TNF receptor linked to the Fc portion of human immunoglobulin G1 (IgG1) by three disulfide bonds. The protein is produced using recombinant DNA technology in a mammalian Chinese hamster ovarian cell line and consists of 934 amino acids. ${ }^{7,8}$ Despite the presence of an Fc region, etanercept does not promote complement-mediated cell lysis in vitro as opposed to the monoclonal antibodies that do exhibit this in vitro. ${ }^{9}$ 
Etanercept acts as a competitive inhibitor of TNF, a naturally occurring proinflammatory cytokine produced by many different cell types including activated $\mathrm{T}$ cells, fibroblasts, adipocytes, and keratinocytes. TNF acts as a key mediator of inflammatory processes in the pathogenesis of psoriasis and psoriatic arthritis.

Etanercept inhibits the activity of TNF by competitively binding it, thus antagonizing interactions with TNF receptors on cell surface, and preventing activation of the inflammatory cascade. It is unique among TNF blocking biologic agents for psoriasis in that it mimics the activity of naturally occurring soluble TNF receptors, and prevents binding of free, soluble, non-membrane-bound TNF. There are two distinct receptors for naturally-occurring TNF: p55, also known as TNF- $\beta$ or lymphotoxin, and $\mathrm{p} 75$, which is TNF- $\alpha$. Biological activity of TNF is modulated through these receptors. ${ }^{10-12}$

Elevated levels of TNF- $\alpha$ have been found in fluid from patients with psoriatic arthritis, psoriatic skin lesions, and serum of patients with plaque psoriasis. ${ }^{13} \mathrm{TNF}-\alpha$ stimulates the production of chemokines and the expression of adhesion molecules by keratinocytes and vascular endothelial cells. The release of these signals cause recruitment of additional inflammatory cells into the plaque, amplifying the inflammatory process within psoriatic plaques. ${ }^{14}$ Treatment with etanercept has been shown to reduce several markers of inflammation within biopsied plaques. ${ }^{15}$ Moreover, serum and lesional TNF- $\alpha$ levels directly correlate with the severity of psoriasis, as measured by the psoriasis area and severity index (PASI) score. ${ }^{16,17}$ Additionally, the dimeric nature of etanercept protein allows the binding of TNF- $\alpha$ at an affinity that is 50 to 1000 times greater than in naturally occurring TNF- $\alpha$ receptors. ${ }^{8}$

Etanercept may also weakly interact with the TNF- $\beta$ receptor, which acts on B-cells, T-cells, NK-cells and lymphoid architecture to stimulate immunoreactivity. ${ }^{10,11}$ TNF- $\beta$ inhibition has been shown to be effective in moderating the symptoms of psoriasis. However, onercept, a human recombinant soluble TNF- $\beta$ receptor, was discontinued in April 2005 during Phase III clinical trials for moderate to severe psoriasis after two patients developed sepsis. ${ }^{18}$

\section{Pharmacokinetics}

Etanercept has a mean half-life of approximately 4.3 days (70-100 hours) and reaches peak concentration at approximately 48 to 60 hours with an absolute bioavailability of $58 \% .{ }^{19}$ Of the currently marketed anti-TNF agents approved for psoriasis, etanercept exhibits the shortest half-life. Potential advantages incurred by the shorter half-life can include more rapid drug elimination in the setting of a serious adverse event including an infectious episode. No formal pharmacokinetics studies have been conducted to investigate the metabolism of etanercept. However, using radiolabelled etanercept in patients with acute renal and hepatic failure did not demonstrate abnormally increased serum etanercept concentrations. Therefore, no dosage adjustment is needed in the presence of renal and hepatic impairment. ${ }^{20}$ There are no apparent age- or gender-related pharmacokinetic differences. However, in children aged 4 to 8 years, the clearance of etanercept may be slightly reduced though no dose adjustment is warranted. 19,21,22 Furthermore, no dose adjustment is needed when etanercept is co-administered with methotrexate, warfarin, or digoxin. ${ }^{23-25}$

\section{Indications and dosing}

In the United States, etanercept is indicated for the treatment of adult patients (18 years or older) with chronic moderate to severe plaque psoriasis who are candidates for systemic therapy or phototherapy. ${ }^{9}$ The recommended induction dose of etanercept in the treatment of moderate-to-severe plaque psoriasis is $50 \mathrm{mg}$ twice weekly for 3 months followed by a maintenance dosage of $50 \mathrm{mg}$ weekly. ${ }^{26}$ There are data to demonstrate once-weekly administration of etanercept $50 \mathrm{mg}$ is as efficacious and well tolerated as etanercept $25 \mathrm{mg}$ biweekly providing a more convenient dosing regimen. ${ }^{27}$

In Europe, etanercept is indicated for the treatment of adults with chronic moderate to severe plaque psoriasis who have failed to respond to, or who have a contraindication to, or who are intolerant to other systemic therapies or photochemotherapy including cyclosporine, methotrexate or PUVA. ${ }^{28}$ It is also indicated in the treatment of active and progressive psoriatic arthritis in adults who have failed disease-modifying anti-rheumatic drug (DMARD) therapy. The European dermatology expert group recommends the same dosing regimen as the one used in the US for the treatment of plaque psoriasis. ${ }^{29}$

\section{Monotherapy}

Etanercept has been shown to be effective as monotherapy for moderate to severe plaque psoriasis with dose dependent efficacy. ${ }^{26,30-38}$ Published data from large randomized control trials conducted by various investigators from the Etanercept Psoriasis Study Group have found that at 12 weeks, 34\% of patients receiving $25 \mathrm{mg}$ of etanercept biweekly (biw) and $47 \%$ to $49 \%$ of patients receiving $50 \mathrm{mg}$ biw, had improvement of PASI 75 from baseline compared with $3 \%$ to $4 \%$ of patients receiving placebo. ${ }^{30-32}$ This response is dose dependent with faster and 
more significant responses occurring in patients taking $50 \mathrm{mg}$ biw. ${ }^{30,31}$ Papp et al ${ }^{30}$ in their Phase III trial of 583 patients reported that by week 4, only the $50 \mathrm{mg}$ biw group had a statistically significant number of people (10\%) achieving PASI 75 , while the $25 \mathrm{mg}$ biw group achieved statistical significance at week 8 . At week 12, the difference between the etanercept $50 \mathrm{mg}$ biw group and the $25 \mathrm{mg}$ biw group were statistically significant with a greater response of $47 \%$ compared to $34 \%$ of patients with PASI 75, respectively. ${ }^{30,31}$

Clinical response may continue to improve or be maintained with sustained etanercept therapy. Evidence from the two large Phase III randomized-controlled trials (RCT) with 6 months follow-up of patients continuing treatment found that $44 \%$ to $45 \%$ of patients receiving $25 \mathrm{mg}$ biw and $54 \%$ to $59 \%$ of patients receiving $50 \mathrm{mg}$ biw achieved PASI-75. ${ }^{30,31}$ Sustained treatment up to 96 weeks in an openlabel extension of a large $(n=591)$ RCT showed that longterm etanercept $50 \mathrm{mg}$ biw can maintain psoriasis response. ${ }^{39}$ The percent of patients who achieved PASI 75 was $47 \%$ at 12 weeks, $60 \%$ at 24 weeks, $63 \%$ at 48 weeks, and $51 \%$ at 96 weeks.

There is evidence from Papp et al that decreasing the $50 \mathrm{mg}$ biw dose to $25 \mathrm{mg}$ biw at 12 weeks results in maintenance of benefits and even improved response in some patients. ${ }^{30}$ They found that stepped down treatment from $50 \mathrm{mg}$ to $25 \mathrm{mg}$ biw after 12 weeks of treatment, resulted in $54 \%$ of patients with PASI-75 at 24 weeks compared to $45 \%$ of patients who had received $25 \mathrm{mg}$ biw for 24 weeks. $77 \%$ of patients were able to maintain a PASI 75 score and 97\% maintained a PASI score greater than $50 \%$ while on the reduced etanercept dose. Additionally, about one third of the 88 people who did not achieve a PASI 75 score at 12 weeks while taking $50 \mathrm{mg}$ biw did at 24 weeks despite the decrease in dose. ${ }^{30}$

These data suggest that most people may benefit from the faster, more effective resolution at the higher dose of $50 \mathrm{mg}$ biw, and will be able to maintain the benefits of etanercept induction dose while only taking $25 \mathrm{mg}$ biw after the 12 weeks. In patients who do demonstrate loss of clinical response when transitioned from $50 \mathrm{mg}$ to $25 \mathrm{mg}$ BIW, ineffective dosing of patients with higher body mass index (BMI) may account for some of these cases. ${ }^{40}$ In general, obese patients (BMI greater than 30) are poorer responders. Studies have shown that adipose tissue produces elevated levels of TNF- $\alpha .{ }^{41}$ Since patients that are obese have more adipose tissue than non-obese patients, it is believed that obese patients have elevated TNF- $\alpha$ levels and thus the etanercept dose is more often inadequate.
A recent study evaluated the use of etanercept in children and adolescents (4-17 years of age) with moderate to severe plaque psoriasis. Patients were dosed once weekly with $0.8 \mathrm{mg} / \mathrm{kg}$ of etanercept up to a maximum of $50 \mathrm{mg}$ weekly. The percent of patients who achieved a PASI 75 response from baseline was $57 \%$ compared to $11 \%$ in those patients receiving placebo $(\mathrm{p}<0.001){ }^{42}$

\section{Combination therapy}

The concept of maximizing efficacy and minimizing adverse side effects through the combined use of topical, phototherapy, and systemic agents has been exercised extensively. Combination therapy is most useful to treat patients who have failed monotherapy and in the prevention of step-down deterioration. Treatment with prebiologic agents is limited to rotational therapy due to concerns of cumulative toxicity and major organ adverse side effects; the advent of biologic agents has increased feasibility of continuous therapy for long-term control, particularly in patients with recalcitrant disease. Additive immunosuppression may be a concern. For this reason, biologics including etanercept are not routinely used in combination with drugs such as cyclosporine.

\section{Etanercept and topical corticosteroids}

A consensus statement from the European dermatology expert group on the use of etanercept encourages the use of topical corticosteroids in combination with etanercept, particularly at the start of therapy to increase the speed of therapeutic response. ${ }^{29}$ Combination of etanercept with phototherapy is of greater concern due to etanercept's immunosuppressive side effects and phototherapy's possible increased risk of skin cancers. Although there are no data on the concomitant use of etanercept and PUVA, this combination should only be used with caution in fair-skinned patients as the increased risk of skin cancers has been demonstrated in patients receiving cyclosporine who were previously treated with PUVA. ${ }^{43,44}$

\section{Etanercept and narrowband ultraviolet light $B$ (NBUVB)}

A multicenter, open-label, single-arm prospective study (the Utilization of NB-UVB Light Therapy and Etanercept for the Treatment of Psoriasis [UNITE] study) evaluated the efficacy of etanercept $50 \mathrm{mg}$ twice weekly in combination with NB-UVB 3 times weekly in patients with moderate to severe psoriasis $(\mathrm{n}=86) .{ }^{45}$ After 12 weeks, the percent of patients achieving a PASI 75 response was $84.4 \%$. The percentage of patients who achieved a PASI 90 or PASI 100 response was 
$58.1 \%$ and $26 \%$, respectively. In this study, the combination of etanercept and NB-UVB was efficacious and generally well tolerated with no increase in photosensitivity noted. The addition of NB-UVB may serve as an option for the subset of patients who experience worsening of psoriasis after "stepping-down" from the induction dose. Caution should be used when starting etanercept for patients with known or suspected skin cancers due to case reports of squamous cell cancers (SCCs) that grew rapidly from pre-existing suspicious lesions after initiation of etanercept therapy. ${ }^{46}$

\section{Etanercept and methotrexate}

Most data involving the combination of etanercept with DMARDs, particularly, methotrexate are from rheumatology in the treatment of rheumatoid arthritis and psoriatic arthritis. The safety of this combination has been evaluated in rheumatoid arthritis in two large randomized, controlled, doubleblind clinical trials: the Trial of Etanercept and methotrexate with Radiographic Patient Outcomes $(\text { TEMPO })^{47}(n=682)$ and the Combination of Methotrexate and Etanercept in Active Early Rheumatoid Arthritis $(\text { COMET })^{48}(\mathrm{n}=542)$. Each study found the combination of methotrexate and etanercept to be generally safe and well-tolerated with no statistically significant increased rates and types of adverse events compared to the monotherapy groups.

Etanercept is approved for the treatment of both psoriasis and psoriatic arthritis. Clinical trials involving psoriatic arthritis allow concurrent use of systemic agents including methotrexate and prednisone. However, trials in psoriasis population often require that patients "wash out" from such medications, thus most available data on combination therapy are from case reports. ${ }^{49-52}$

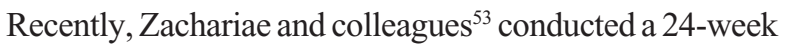
RCT evaluating combination therapy with etanercept and methotrexate in 59 patients with plaque psoriasis who had previously failed methotrexate monotherapy. Patients were randomized into two groups, one which received etanercept with methotrexate tapered up to week 4 , and the other received etanercept combined with continued methotrexate treatment. In both arms, patients received etanercept $50 \mathrm{mg}$ twice weekly for 12 weeks, and then $25 \mathrm{mg}$ twice weekly for the remaining 12 weeks. The study reported a significantly higher proportion of patients achieving a PGA of "clear" or "almost clear" and PASI 50, PASI 75, and PASI 90 at both 12 weeks and 24 weeks for combination treatment than etanercept/methotrexate taper. There was very little difference in adverse events in patients receiving combination therapy versus etanercept monotherapy. The combination of methotrexate with etanercept offers a promising option for patients suffering from psoriasis despite monotherapy with methotrexate or etanercept.

\section{Etanercept and acitretin}

There are few studies evaluating the efficacy of acitretin with biologics. One case series described eight patients who had been treated with biologic agents and acitretin. ${ }^{54}$ Five of the eight patients received treatment with etanercept $(25-50 \mathrm{mg}$ once to twice weekly) and acitretin (25-50 mg every other day to daily). One of these patients was later changed to adalimumab $40 \mathrm{mg}$ weekly plus acitretin. Other than mild transient cholesterol elevation in one patient, there were no reported adverse effects.

A retrospective review $(n=15)$ described patients treated with acitretin and a biologic agent, four received etanercept. ${ }^{45}$ The average time of treatment with both agents was 7.28 months. Overall, 29\% of patients were clear of psoriasis, $43 \%$ showed $90 \%$ improvement, $14 \%$ showed $75 \%$ improvement, and $7.15 \%$ showed no change. One patient with a previous history of SCC continued to develop multiple SCCs while on etanercept therapy. After acitretin ( $25 \mathrm{mg}$ every other day) was added, the rate of new SCC development decreased from an average of three SCCs diagnosed every two weeks to actinic keratosis with no new SCCs for 18 months. Another patient who was treated with acitretin and etanercept for 3 years developed non-Hodgkin's lymphoma, at which point etanercept was discontinued. The authors concluded that acitretin may be useful in combination with biologic agents, but further studies to determine the long-term safety and efficacy were needed.

A randomized, investigator-blinded pilot trial treated 60 patients with either etanercept $25 \mathrm{mg}$ twice weekly, acitretin $0.4 \mathrm{mg} / \mathrm{kg}$ daily, or etanercept $25 \mathrm{mg}$ once weekly plus acitretin $0.4 \mathrm{mg} / \mathrm{kg}$ daily. ${ }^{55}$ The PASI 75 response after 24 weeks was $45 \%$ in the etanercept group, $30 \%$ in the acitretin group and $44 \%$ in the combination group. No significant differences in the mean value of liver enzymes, cholesterol, and triglycerides were reported in any of the three groups at all times investigated. The results from this study demonstrated that combination of acitretin and etanercept may serve as another long-term control option for psoriasis, or alternatively, etanercept could be added in patients inadequately treated with acitretin monotherapy. This combination greatly reduces the cost of treatment compared with etanercept $25 \mathrm{mg}$ twice weekly while achieving similar efficacy.

\section{Toxicities and adverse reactions}

Etanercept has been used worldwide in over half a million patients, with chronic conditions such as severe arthritis or 
psoriasis for more than 16 years. Etanercept has undergone numerous short-term safety analyses in rigorous clinical trials in rheumatoid arthritis, psoriatic arthritis, and psoriasis and long-term safety analyses in both controlled clinical trials and post-marketing surveillance. ${ }^{10,31,56,57}$ Despite this longterm and extensive human experience, to date, the FDA has not reported any serious adverse events based on evidencebased, Grade A criteria (ie, statistically slight increased risk when comparing large etanercept treated population vs placebo treated population involving subjects who are basically healthy and not a carrier of chronic infection such as tuberculosis [TB] or hepatitis).

\section{Injection site reaction}

The most common adverse effect of etanercept appears to be a mild, transient injection site reaction, generally occurring during initial administration lasting between 3 and 5 days. Approximately, $37 \%$ of patients will experience this side effect. Appropriate medication administration including rotation of sites should be discussed with patients at teaching session.

\section{Infections}

The next most common side effect is an increased risk of infections, particularly upper respiratory tract infections and cold-like illnesses. Patients may have increased susceptibility to infections by intracellular organisms including TB and listeria. However, there is no evidencebased data demonstrating increased TB reactivation in etanercept users compared to the general population unlike TNF-monoclonal antibodies. ${ }^{33,46,47}$ Some studies demonstrate that $\mathrm{TB}$ reactivation in etanercept users has an increased risk of presenting as an atypical or disseminated infection. ${ }^{58}$ In contrast to etanercept, adalimumab and infliximab are monoclonal antibodies that bind to soluble and transmembrane TNF- $\alpha$ and may cause complementmediated cell lysis of macrophages and monocytes; therefore, they appear to interfere to a greater extent with the host granulomatous defense against intracellular organisms such as TB.

The FDA, in their post-marketing surveillance database has recently strengthened their black box warning on all TNF-antagonists for fungal infections, with a specific focus on histoplasmosis. Of the 240 reports of histoplasmosis in patients receiving TNF-antagonists submitted to the FDA, 17 cases were related to etanercept (7\%), with the rest related to infliximab (207 cases; 86\%) and adalimumab (16 cases; 6.6\%). Patients from the endemic
Ohio and Mississippi River valley regions made up 80\% of these cases. ${ }^{59}$

Long-term follow up of etanercept therapy up to 96 weeks found that exposure-adjusted rates of noninfectious and infectious adverse events were similar between the treatment group at weeks 12 and 96, and between the treatment group and placebo. ${ }^{39}$

\section{Hepatitis B}

There have been case reports of hepatitis B virus (HBV) reactivation in patients who are chronic carriers while receiving etanercept. ${ }^{9,60}$ The incidence of HBV reactivation is higher in patients receiving concomitant immunosuppressive therapy. ${ }^{9,60}$ Currently, the safety or efficacy of treating patients who are HBV carriers with anti-viral therapy in conjunction with TNF- $\alpha$ antagonists to prevent HBV reactivation is not known. Caution should be taken when etanercept is considered in patients who are carriers of HBV.

\section{Hepatitis C}

In contrast to its effects on $\mathrm{HBV}$, there have been case reports of etanercept use in patients with concurrent hepatitis $\mathrm{C}$ virus infection without worsening of hepatitis or interfering with hepatitis treatment. ${ }^{61}$ Etanercept is not indicated for the treatment of chronic HCV although there has been one phase II randomized controlled study evaluating etanercept use in patients with chronic $\mathrm{HCV}$. Etanercept was given as an adjuvant to interferon and ribavirin in 50 patients with chronic $\mathrm{HCV}$ with reports of an increased virologic response at week 24 (etanercept $63 \%$ vs placebo $32 \%$ ) and no statistically significant differences in hematological adverse effects. ${ }^{62}$ Furthermore, there have been case reports that etanercept may be a safe option for treating psoriatic arthritis and psoriasis in patients with concurrent chronic HCV infection. ${ }^{63}$

\section{Others}

Serious infections and sepsis, including fatalities, have been reported in patients undergoing etanercept therapy. ${ }^{9}$ There is a greater risk of mortality in patients who become septic while receiving etanercept. ${ }^{64,65}$ Several of the serious infections have occurred in patients on concomitant immunosuppressive therapy that, in combination with their underlying disease, may predispose this patient population to infections. It is advised that etanercept should be discontinued until resolution of serious infection or sepsis. Further, serious adverse events such as demyelinating disease, congestive heart failure, hematological abnormalities, and 
systemic lupus-like condition are rare and primarily based on anecdotal evidence. ${ }^{64,65}$

Another consideration for patients treated with long-term TNF- $\alpha$ antagonists, including etanercept, is the possibility of increased weight gain. ${ }^{66,67}$ Additionally, etanercept antibodies may be encountered in up to $16 \%$ of patients; ${ }^{68}$ however these antibodies are non-neutralizing and do not appear to effect efficacy or safety profiles. ${ }^{9}$

\section{Malignancy}

The incidence of malignancy was investigated in the 96-week trial of etanercept ${ }^{39}$ and compared to the incidence of cancer in the population. The authors found 9 malignancies during the open-label follow up and compared the incidence to national cancer databases. Observed numbers of total malignancies were not statistically significantly different from the expected numbers of total malignancies based on National Cancer Institute data. ${ }^{39}$

The FDA recently issued an Early Communication regarding the possible association between TNF blockers and the development of lymphoma and other malignancies in children and young adults. Over a 10-year interval, beginning in 1998 through 2008, there were approximately 30 reports of cancer occurring in children and young adults who began taking TNF inhibitors (along with other immunosuppressive medications such as methotrexate, azathioprine or 6-mecaptopurine), when they were aged 18 or less. Approximately half of the cancers reported were lymphoma. At the current time, the FDA believes that the potential benefits of TNF inhibitors outweigh the potential risks but further long-term studies are necessary to provide definitive answers about whether the use of TNF inhibitors in children increase the occurrence of cancers. ${ }^{69}$

\section{Pregnancy}

Etanercept and other TNF- $\alpha$ antagonists are considered category B drugs for pregnancy. Limited data are available on the safety of etanercept in pregnant or lactating patients. Because animal reproductive studies are not always predictive of human response, this drug should not be used in pregnancy unless clearly needed. It is not known whether etanercept is absorbed systemically after ingestion and so there is a potential for serious adverse reactions to the nursing infant. A decision should be made whether to discontinue etanercept before nursing. There is no evidence supporting embryo toxicity, teratogenicity or increased pregnancy loss. ${ }^{70,71}$ Currently, there are no studies describing the effect of etanercept on human lactation or the nursing infant. Thus, the use of etanercept during pregnancy and lactation is not recommended. Caution is advised when prescribing to women of reproductive age. ${ }^{72}$

\section{Follow-up}

A baseline and annual Mantoux test using purified protein derivative (PPD) is required to monitor for TB. Although widely used, the PPD test has a number of limitations including lack of sensitivity in immunocompromised and active TB patients and lack of specificity in bacille Calmette-Guérin (BCG)-exposed individuals. Two novel FDA approved assays for detecting latent $\mathrm{TB}$ can be considered. The QuantiFERON ${ }^{\circledR}$ TB Gold test (QFT-G; Cellestis Ltd, Carnegie, Australia) and T-Spot ${ }^{\circledR}$ TB (Oxford Immunotec, Abingdon, UK) may offer greater sensitivity and specificity than Mantoux test, especially in context of immunosuppression and previous BCG vaccination. ${ }^{73}$ Preliminary studies using QFT-G in screening for TB in rheumatoid arthritis patients undergoing TNF-inhibitor therapy has suggested that it is sensitive for detecting latent TB in patients previously exposed to various immunosuppressive therapies at the time of the QFT-G testing. ${ }^{74}$

Complete blood count and liver function tests may also be obtained at baseline with periodic monitoring. History and physical examination should be obtained while a patient is on this medication. Due to reports of hepatitis B reactivation, screening for hepatitis B and C should be considered in the appropriate clinical setting.

\section{Guidelines for use}

1. Etanercept is indicated for patients with moderate to severe psoriasis, adult and juvenile idiopathic (formerly rheumatoid) arthritis (for patients as young as 4 years of age), and ankylosing spondylitis.

2. Psoriatic arthritis dosing is $25 \mathrm{mg}$ twice weekly or $50 \mathrm{mg}$ weekly, given subcutaneously.

3. PPD testing should be performed on all patients prior to starting therapy.

4. Live vaccines should not be used in combination with etanercept or other TNF inhibitors. Biologically inactive or recombinant vaccines may be used; however patients should be warned the immune response to these vaccines may be compromised.

5. Etanercept should not be used in patients with a history of multiple sclerosis or other demyelinating diseases. First degree relatives of patients with multiple sclerosis also should not use etanercept.

6. Etanercept should be used with caution in patients with congestive heart failure (CHF). Patients with New York Heart Association class III or IV CHF should not use 
TNF inhibitors. Patients with New York Heart Association class I or II CHF should undergo echocardiogram testing. If their ejection fraction is $<50 \%$, etanercept should not be used.

7. Due to reports of hepatitis B reactivation after starting etanercept, screening for hepatitis B infection should be performed in the appropriate clinical setting.

8. Etanercept is pregnancy category B and should only be used during pregnancy if clearly needed.

9. Etanercept is contraindicated in patients with sepsis or other active, serious infections.

10. The needle cover of the prefilled syringes contains latex and should not be used in patients with latex sensitivity.

\section{Disclosures}

The authors have no conflicts of interest to disclose.

\section{References}

1. Dubertret L, Mrowietz U, Ranki A, van de Kerkhof PC, Chimenti $\mathrm{S}$, Lotti $\mathrm{T}$, et al. European patient perspectives on the impact of psoriasis: the EUROPSO patient membership survey. $\mathrm{Br} J$ Dermatol. 2006;155:729-736.

2. Gottlieb AB, Chao C, Dann F. Psoriasis comorbidities. J Dermatolog Treat. 2008;19:5-21.

3. Finlay AY, Coles EC. The effect of severe psoriasis on the quality of life of 369 patients. Br J Dermatol. 1995;132:236-244.

4. Krueger G, Koo J, Lebwohl M, Menter A, Stern RS, Rolstad T. The impact of psoriasis on quality of life: results of a 1998 National Psoriasis Foundation patient-membership survey. Arch Dermatol. 2001;137:280-284.

5. Wu Y, Mills D, Bala M. Psoriasis: cardiovascular risk factors and other disease comorbidities. J Drugs Dermatol. 2008;7:373-377.

6. Christophers E. Comorbidities in psoriasis. Clin Dermatol. 2007;25:529-534

7. Dembic Z, Loetscher H, Gubler U, Pan YC, Lahm HW, Gentz R, et al. Two human TNF receptors have similar extracellular, but distinct intracellular, domain sequences. Cytokine. 1990;2:231-237.

8. Mohler KM, Torrance DS, Smith CA, Goodwin RG, Stremler KE, Fung VP, et al. Soluble tumor necrosis factor (TNF) receptors are effective therapeutic agents in lethal endotoxemia and function simultaneously as both TNF carriers and TNF antagonists. J Immunol. 1993;151:1548-1561.

9. Etanercept [package insert]. Seattle, WA: Immunex Corporation and Wyeth-Ayerst Pharmaceuticals; 2008.

10. Keystone EC. Safety of biologic therapies - an update. $J$ Rheumatol Suppl. 2005;74:8-12.

11. Spahn TW, Eugster HP, Fontana A, Domschke W, Kucharzik T. Role of lymphotoxin in experimental models of infectious diseases: potential benefits and risks of a therapeutic inhibition of the lymphotoxin-beta receptor pathway. Infect Immun. 2005;73:7077-7088.

12. Gudbrandsdottir S, Larsen R, Sorensen LK, Nielsen S, Hansen MB, Svenson M, et al. TNF and LT binding capacities in the plasma of arthritis patients: effect of etanercept treatment in juvenile idiopathic arthritis. Clin Exp Rheumatol. 2004;22:118-124.

13. Ettehadi P, Greaves MW, Wallach D, Aderka D, Camp RD. Elevated tumour necrosis factor-alpha (TNF-alpha) biological activity in psoriatic skin lesions. Clin Exp Immunol. 1994;96:146-151.

14. Krueger JG. The immunologic basis for the treatment of psoriasis with new biologic agents. $J$ Am Acad Dermatol. 2002;46:1-23; quiz-6.
15. Catrina AI, Lampa J, Ernestam S, af Klint E, Bratt J, Klareskog L, et al. Anti-tumour necrosis factor (TNF)-alpha therapy (etanercept) down-regulates serum matrix metalloproteinase (MMP)-3 and MMP-1 in rheumatoid arthritis. Rheumatology (Oxford). 2002;41:484-489.

16. Bonifati C, Carducci M, Cordiali Fei P, Trento E, Sacerdoti G, Fazio M, et al. Correlated increases of tumour necrosis factor-alpha, interleukin- 6 and granulocyte monocyte-colony stimulating factor levels in suction blister fluids and sera of psoriatic patients-relationships with disease severity. Clin Exp Dermatol. 1994;19:383-387.

17. Mussi A, Bonifati C, Carducci M, D’Agosto G, Pimpinelli F, D'Urso D, et al. Serum TNF-alpha levels correlate with disease severity and are reduced by effective therapy in plaque-type psoriasis. $J$ Biol Regul Homeost Agents. 1997;11:115-118.

18. Bock D, Philipp S, Wolff G. Therapeutic potential of selectin antagonists in psoriasis. Expert Opin Investig Drugs. 2006;15:963-979.

19. Zhou H. Clinical pharmacokinetics of etanercept: a fully humanized soluble recombinant tumor necrosis factor receptor fusion protein. J Clin Pharmacol. 2005;45:490-497.

20. Don BR, Spin G, Nestorov I, Hutmacher M, Rose A, Kaysen GA. The pharmacokinetics of etanercept in patients with end-stage renal disease on haemodialysis. J Pharm Pharmacol. 2005;57:1407-1413.

21. Zhou H, Buckwalter M, Boni J, Mayer P, Raible D, Wajdula J, et al. Population-based pharmacokinetics of the soluble TNFr etanercept: a clinical study in 43 patients with ankylosing spondylitis compared with post hoc data from patients with rheumatoid arthritis. Int J Clin Pharmacol Ther. 2004;42:267-276.

22. Nestorov I, Zitnik R, DeVries T, Nakanishi AM, Wang A, Banfield C. Pharmacokinetics of subcutaneously administered etanercept in subjects with psoriasis. Br J Clin Pharmacol. 2006;62:435-445.

23. Zhou H, Mayer PR, Wajdula J, Fatenejad S. Unaltered etanercept pharmacokinetics with concurrent methotrexate in patients with rheumatoid arthritis. J Clin Pharmacol. 2004;44:1235-1243.

24. Zhou H, Parks V, Patat A, Le Coz F, Simcoe D, Korth-Bradley J. Absence of a clinically relevant interaction between etanercept and digoxin. J Clin Pharmacol. 2004;44:1244-1251.

25. Zhou H, Patat A, Parks V, Buckwalter M, Metzger D, Korth-Bradley J. Absence of a pharmacokinetic interaction between etanercept and warfarin. J Clin Pharmacol. 2004;44:543-550.

26. Menter A, Gottlieb A, Feldman SR, Van Voorhees AS, Leonardi CL, Gordon KB et al. Guidelines of care for the management of psoriasis and psoriatic arthritis: Section 1. Overview of psoriasis and guidelines of care for the treatment of psoriasis with biologics. J Am Acad Dermatol. 2008;58:826-850

27. van de Kerkhof PC, Segaert S, Lahfa M, Luger TA, Karolyi Z, Kaszuba A, et al. Once weekly administration of etanercept $50 \mathrm{mg}$ is efficacious and well tolerated in patients with moderate-to-severe plaque psoriasis: a randomized controlled trial with open-label extension. $\mathrm{Br} \mathrm{J}$ Dermatol. 2008;159:1177-1185.

28. Enbrel ${ }^{\circledR}$ Summary of Product Characteristics. Wyeth Europa Ltd, Maidenhead, 2005.

29. Boehncke WH, Brasie RA, Barker J, Chimenti S, Dauden E, de Rie M, et al. Recommendations for the use of etanercept in psoriasis: a European dermatology expert group consensus. J Eur Acad Dermatol Venereol. 2006;20:988-998.

30. Papp KA, Tyring S, Lahfa M, Prinz J, Griffiths CE, Nakanishi AM, et al. A global phase III randomized controlled trial of etanercept in psoriasis: safety, efficacy, and effect of dose reduction. Br J Dermatol. $2005 ; 152: 1304-1312$

31. Leonardi CL, Powers JL, Matheson RT, Goffe BS, Zitnik R, Wang A, et al. Etanercept as monotherapy in patients with psoriasis. $N$ Engl $J$ Med. 2003;349:2014-2022.

32. Tyring S, Gottlieb A, Papp K, Gordon K, Leonardi C, Wang A, et al. Etanercept and clinical outcomes, fatigue, and depression in psoriasis: double-blind placebo-controlled randomised phase III trial. Lancet. 2006;367:29-35

33. Gottlieb AB, Matheson RT, Lowe N, Krueger GG, Kang S, Goffe BS, et al. A randomized trial of etanercept as monotherapy for psoriasis. Arch Dermatol. 2003;139:1627-1632; discussion 32. 
34. Moore A, Gordon KB, Kang S, Gottlieb A, Freundlich B, Xia HA, et al. A randomized, open-label trial of continuous versus interrupted etanercept therapy in the treatment of psoriasis. J Am Acad Dermatol. 2007;56:598-603.

35. Feldman SR, Kimball AB, Krueger GG, Woolley JM, Lalla D, Jahreis A. Etanercept improves the health-related quality of life of patients with psoriasis: results of a phase III randomized clinical trial. $J$ Am Acad Dermatol. 2005;53:887-889.

36. Gordon K, Korman N, Frankel E, Wang H, Jahreis A, Zitnik R, et al. Efficacy of etanercept in an integrated multistudy database of patients with psoriasis. J Am Acad Dermatol. 2006;54:S101-S111.

37. Gottlieb AB, Leonardi CL, Goffe BS, Ortonne JP, van der Kerkhof PC, Zitnik R, et al. Etanercept monotherapy in patients with psoriasis: a summary of safety, based on an integrated multistudy database. $J \mathrm{Am}$ Acad Dermatol. 2006;54:S92-S100.

38. Krueger GG, Langley RG, Finlay AY, Griffiths CE, Woolley JM, Lalla D, et al. Patient-reported outcomes of psoriasis improvement with etanercept therapy: results of a randomized phase III trial. $\mathrm{Br} J$ Dermatol. 2005;153:1192-1199.

39. Tyring S, Gordon KB, Poulin Y, Langley RG, Gottlieb AB, Dunn M, et al. Long-term safety and efficacy of $50 \mathrm{mg}$ of etanercept twice weekly in patients with psoriasis. Arch Dermatol. 2007;143:719-726.

40. Strober B GA, Leonardi C, et al. Poster P2890 presented at: American Academy of Dermatology 64th Annual Meeting, March 3-7, 2006. San Francisco, California.

41. Hotamisligil GS, Arner P, Caro JF, Atkinson RL, Spiegelman BM. Increased adipose tissue expression of tumor necrosis factor-alpha in human obesity and insulin resistance. J Clin Invest. 1995;95:2409-2415.

42. Paller AS, Siegfried EC, Langley RG, Gottlieb AB, Pariser D, Landells I, et al. Etanercept treatment for children and adolescents with plaque psoriasis. N Engl J Med. 2008;358:241-251.

43. Marcil I, Stern RS. Squamous-cell cancer of the skin in patients given PUVA and ciclosporin: nested cohort crossover study. Lancet. 2001;358:1042-1045.

44. Paul CF, Ho VC, McGeown C, Christophers E, Schmidtmann B, Guillaume JC, et al. Risk of malignancies in psoriasis patients treated with cyclosporine: a 5 y cohort study. J Invest Dermatol. 2003;120:211-216.

45. Smith EC, Riddle C, Menter MA, Lebwohl M. Combining systemic retinoids with biologic agents for moderate to severe psoriasis. Int $J$ Dermatol. 2008;47:514-518.

46. Smith KJ, Skelton HG. Rapid onset of cutaneous squamous cell carcinoma in patients with rheumatoid arthritis after starting tumor necrosis factor alpha receptor IgG1-Fc fusion complex therapy. $J \mathrm{Am}$ Acad Dermatol. 2001;45:953-956.

47. Klareskog L, van der Heijde D, de Jager JP, Gough A, Kalden J, Malaise M, et al. Therapeutic effect of the combination of etanercept and methotrexate compared with each treatment alone in patients with rheumatoid arthritis: double-blind randomised controlled trial. Lancet. 2004;363:675-681.

48. Emery P, Breedveld FC, Hall S, Durez P, Chang DJ, Robertson D, et al. Comparison of methotrexate monotherapy with a combination of methotrexate and etanercept in active, early, moderate to severe rheumatoid arthritis (COMET): a randomised, double-blind, parallel treatment trial. Lancet. 2008;372:375-382.

49. Cather JC, Menter A. Combining traditional agents and biologics for the treatment of psoriasis. Semin Cutan Med Surg. 2005;24:37-45.

50. Strober BE. Successful treatment of psoriasis and psoriatic arthritis with etanercept and methotrexate in a patient newly unresponsive to infliximab. Arch Dermatol. 2004;140:366.

51. Strober BE, Clarke S. Etanercept for the treatment of psoriasis: combination therapy with other modalities. J Drugs Dermatol. 2004;3:270-272.

52. Driessen RJ, van de Kerkhof PC, de Jong EM. Etanercept combined with methotrexate for high-need psoriasis. Br J Dermatol. 2008;159:460-463.

53. Zachariae CN-JM, Reunala T, Lorentzen H, et al. The Combination of etanercept and methotrexate increases the effectiveness of treatment in active psoriasis despite inadequate effecdt of methotrexate therapy. Acta Derm Venereol. 2008;88:495-501.
54. Conley J, Nanton J, Dhawan S, Pearce DJ, Feldman SR. Novel combination regimens: biologics and acitretin for the treatment of psoriasis - a case series. J Dermatolog Treat. 2006;17:86-89.

55. Gisondi P, Del Giglio M, Cotena C, Girolomoni G. Combining etanercept and acitretin in the therapy of chronic plaque psoriasis: a 24-week, randomized, controlled, investigator-blinded pilot trial. $\mathrm{Br} \mathrm{J}$ Dermatol. 2008;158:1345-1349.

56. Papp KA. Etanercept in psoriasis. Expert Opin Pharmacother. 2004;5:2139-2146.

57. Lee SJ, Kavanaugh A. Biologic agents in rheumatology: safety considerations. Rheum Dis Clin North Am. 2006;32(Suppl)1:3-10.

58. Mohan AK, Cote TR, Block JA, Manadan AM, Siegel JN, Braun MM. Tuberculosis following the use of etanercept, a tumor necrosis factor inhibitor. Clin Infect Dis. 2004;39:295-299.

59. US Food and Drug Administration. Information for Healthcare Professionals. Cimzia (certolizumab pegol), Enbrel (etanercept), Humira (adalimumab), and Remicade (infliximab) 2008. Available at: http://www.fda.gov/cder/drug/infopage/TNF_blockers/default.htm.

60. Montiel PM, Solis JA, Chirinos JA, Casis B, Sanchez F, Rodriguez S. Hepatitis B virus reactivation during therapy with etanercept in an $\mathrm{HBsAg}-$ negative and anti-HBs-positive patient. Liver Int. 2008;28:718-720.

61. Nathan DM, Angus PW, Gibson PR. Hepatitis B and C virus infections and anti-tumor necrosis factor-alpha therapy: guidelines for clinical approach. J Gastroenterol Hepatol. 2006;21:1366-1371.

62. Zein NN. Etanercept as an adjuvant to interferon and ribavirin in treatment-naive patients with chronic hepatitis $\mathrm{C}$ virus infection: a phase 2 randomized, double-blind, placebo-controlled study. J Hepatol. 2005:42:315-322.

63. Magliocco MA, Gottlieb AB. Etanercept therapy for patients with psoriatic arthritis and concurrent hepatitis $\mathrm{C}$ virus infection: report of 3 cases. J Am Acad Dermatol. 2004;51:580-584.

64. Lovell DJ, Reiff A, Ilowite NT, Wallace CA, Chon Y, Lin SL, et al. Safety and efficacy of up to eight years of continuous etanercept therapy in patients with juvenile rheumatoid arthritis. Arthritis Rheum. 2008;58:1496-1504.

65. Papp KA. The safety of etanercept for the treatment of plaque psoriasis. Ther Clin Risk Manag. 2007;3:245-258.

66. Saraceno R, Schipani C, Mazzotta A, Esposito M, Di Renzo L, De Lorenzo A, et al. Effect of anti-tumor necrosis factor-alpha therapies on body mass index in patients with psoriasis. Pharmacol Res. 2008:57:290-295.

67. Gisondi P, Cotena C, Tessari G, Girolomoni G. Anti-tumour necrosis factor-alpha therapy increases body weight in patients with chronic plaque psoriasis: a retrospective cohort study. J Eur Acad Dermatol Venereol. 2008;22:341-344.

68. Reimold AM. TNFalpha as therapeutic target: new drugs, more applications. Curr Drug Targets Inflamm Allergy. 2002;1:377-392.

69. FDA. Early Communication About an Ongoing Safety Review of Tumor Necrosis Factor Blockers (marketed as Remicade, Enbrel, Humira, and Cimzia). 2008.

70. Roux CH, Brocq O, Breuil V, Albert C, Euller-Ziegler L. Pregnancy in rheumatology patients exposed to anti-tumour necrosis factor (TNF)alpha therapy. Rheumatology. (Oxford). 2007;46:695-698.

71. Hyrich KL, Symmons DP, Watson KD, Silman AJ. Pregnancy outcome in women who were exposed to anti-tumor necrosis factor agents: results from a national population register. Arthritis Rheum. 2006;54:2701-2702.

72. Sanchez Carazo JL, Mahiques Santos L, Oliver Martinez V. Safety of etanercept in psoriasis: a critical review. Drug Saf. 2006;29:675-685.

73. Ferrara G, Losi M, D’Amico R, Roversi P, Piro R, Meacci M, et al. Use in routine clinical practice of two commercial blood tests for diagnosis of infection with Mycobacterium tuberculosis: a prospective study. Lancet. 2006;367:1328-1334.

74. Pratt A, Nicholl K, Kay L. Use of the QuantiFERON TB Gold test as part of a screening programme in patients with RA under consideration for treatment with anti-TNF-alpha agents: the Newcastle (UK) experience. Rheumatology (Oxford). 2007;46:1035-1036. 